\title{
Vaporization order and burning efficiency of crude oils during in-situ burning on water
}

van Gelderen, Laurens; Malmquist, Linus M.V.; Jomaas, Grunde

Published in:

Fuel

Link to article, DOI:

10.1016/j.fuel.2016.11.109

Publication date:

2017

Document Version

Peer reviewed version

Link back to DTU Orbit

Citation $(A P A)$ :

van Gelderen, L., Malmquist, L. M. V., \& Jomaas, G. (2017). Vaporization order and burning efficiency of crude oils during in-situ burning on water. Fuel, 191, 528-537. https://doi.org/10.1016/j.fuel.2016.11.109

\section{General rights}

Copyright and moral rights for the publications made accessible in the public portal are retained by the authors and/or other copyright owners and it is a condition of accessing publications that users recognise and abide by the legal requirements associated with these rights.

- Users may download and print one copy of any publication from the public portal for the purpose of private study or research.

- You may not further distribute the material or use it for any profit-making activity or commercial gain

- You may freely distribute the URL identifying the publication in the public portal

If you believe that this document breaches copyright please contact us providing details, and we will remove access to the work immediately and investigate your claim. 


\section{Vaporization Order and Burning Efficiency of Crude Oils during In-Situ Burning on Water}

Laurens van Gelderen $^{\mathrm{a} *}$, Linus M.V. Malmquist ${ }^{\mathrm{b}}$, Grunde Jomaas ${ }^{\mathrm{a}}$

${ }^{a}$ Department of Civil Engineering, Brovej 1, Technical University of Denmark, 2800 Kgs. Lyngby, Denmark

${ }^{b}$ Department of Plant and Environmental Sciences, Thorvaldsensvej 40, University of Copenhagen, 1871 Frederiksberg C, Denmark

*Corresponding author: lauge@byg.dtu.dk

\section{Abstract}

In order to improve the understanding of the burning efficiency and its observed size dependency of in-situ burning of crude oil on water, the vaporization order of the components in crude oils was studied. The vaporization order of such multicomponent fuels was assessed by studying the surface temperature, flame height, burning rate and burn residues of three alkanes ( $n$-octane, dodecane and hexadecane), a mixture of these alkanes (1:1:1 volumetric ratio) and two crude oils (light and medium-light crudes). The experimental results were compared to four models for the vaporization order of multicomponent fuels. The alkanes were tested as benchmark fuels with a uniform vaporization order, for which all components evaporate simultaneously. As expected, these pure fuels showed a steady state burning with a near-constant surface temperature, flame height and burning rate. The alkane mixture showed similar steady state results but became dominated by the heaviest component towards the end of the burning. These results indicate that the lightest components had been depleted from the mixture. A near-uniform vaporization order in which the lighter components evaporate preferably best matched these results. The crude oils did not show any steady state behavior, but instead had an increasing surface temperature and decreasing burning rate and flame height, indicating a volatility controlled vaporization order. An increasing concentration gradient from the medium to heavy fraction in the burn residues furthermore showed that the vaporization was diffusion-limited. Analysis of 
the heat transfer balance for the crude oils indicated that the energy available for evaporation decreased over time due to increasing heat losses, which were caused by the volatility controlled vaporization order. Presumably, larger scale fires can overcome these heat losses, as they typically have higher burning rates, which increase the heat feedback to the fuel surface and therefore can result in the higher burning efficiencies.

Keywords: Crude oil, vaporization order, heat transfer, burning efficiency

\section{Nomenclature}

\begin{tabular}{llll}
\hline BE & Burning Efficiency (\%) & $\dot{Q}_{c}$ & Heat Release Rate of Combustion (kW) \\
DLV & Diffusion-Limited Vaporization & $\dot{Q}_{c o n v}$ & Convection from flame to fuel (kW) \\
EFV & Equilibrium Flash Vaporization & $\dot{Q}_{\text {evap }}$ & Energy used to evaporate fuel (kW) \\
GC & Gas Chromatography & $\dot{Q}_{g r a d}$ & Energy used to heat fuel layer (kW) \\
ISB & In-Situ Burning & $\dot{Q}_{l o s s}$ & Heat transfer from fuel to water (kW) \\
PGC & Pyrex Glass Cylinder & $\dot{Q}_{n e t}$ & Total net heat from flame to fuel (kW) \\
$\Delta H_{c}$ & Heat of Combustion (kJ/kg) & $\dot{Q}_{r a d}$ & Radiation from flame to fuel (kW) \\
$\Delta H_{g}$ & Heat of Gasification (kJ/kg) & $\dot{Q}_{r e f}$ & Radiative reflection from fuel (kW) \\
$\Delta H_{v}$ & Latent Heat of Vaporization (kJ/kg) & $T_{b}$ & Boiling Point (K) \\
$c_{p}$ & Specific Heat Coefficient (J/kgK) & $T_{s}$ & Surface Temperature (K) \\
$D$ & Diameter (m) & $T_{\infty}$ & Ambient Temperature (K) \\
$L_{F}$ & Flame Height (m) & $\chi_{c}$ & Combustion Efficiency (-) \\
$\dot{m}$ & Burning Rate (g/s) & $\chi_{s}$ & Heat feedback fraction (-) \\
$P e_{m}$ & Peclet Number for Mass Diffusion (-) & & \\
\hline
\end{tabular}




\section{Introduction}

In the Arctic, oil spills pose an upcoming threat to the environment because of the increasing amount of marine transportation and oil exploration [1]. Furthermore, the remoteness and extreme climate of Arctic waters make it difficult for conventional oil spill response methods, such as mechanical recovery, to be deployed effectively $[2,3]$. However, a promising response method that is suitable under these circumstances is in-situ burning (ISB) of the crude oil on the water surface. This technique features simple logistics, can be used in ice-infested waters and can obtain a high burning efficiency $(B E)[4,5]$. A high $B E$ is the primary target for ISB and is defined as the amount of oil (in wt. \%) that is removed from the water surface during the burning. BEs can reach as high as $99 \%$ [6] and as low as 32\% [7], depending on a variety of conditions (e.g. oil type, slick thickness, pool size, emulsification, the weather and presence of ice). Because low BEs are undesired, it is important to understand the processes that control the BE to maximize the potential of ISB operations.

For a multicomponent fuel such as a crude oil, the BE is determined by the type and the quantity of compounds that evaporate from the burning fuel, i.e. the vaporization process. Many of the physical parameters that influence the vaporization have been studied and their effects on the ignitability and BE of crude oil are wellknown. Examples include the regression rate [8], slick thickness [9], heat losses to the water [10], emulsification $[11,12]$, evaporative losses $[11,13]$ and weather conditions [11]. However, the studied parameters cannot be used to explain the apparent pool size dependency of the BE. Small scale studies (e.g., [7, 14, 15]) have consistently reported lower BE values than large scale field studies [16-18] under otherwise similar conditions. BEs of the small scale studies varied between $32-80 \%$, whereas a minimum of $95 \%$ BE was reported for the large scale studies. For ISB to be used successfully as oil spill response method, it is important to ensure that these lower BEs can be avoided during full scale operations.

One aspect of crude oil that has remained relatively unstudied in relation to combustion is its multicomponent nature. The aforementioned studies focused on the quantity and rate of the vaporization process and not the chemical composition that determines the type of compounds that can evaporate. Crude oils consist of 
thousands of different hydrocarbons, each with their own specific density, viscosity, flash point, boiling point $\left(T_{b}\right)$, etc. $[19,20]$. The order in which these compounds evaporate during combustion is here referred to as the vaporization order. Although several models have been suggested in literature for the vaporization order of multicomponent fuels [21-23], there is to our knowledge not a single generally acknowledged model for crude oil combustion. Combined with the physical parameters that determine the vaporization quantity and rate, knowing the vaporization order would result in a good understanding of the vaporization process. This will in turn improve the general understanding of the BE and may present an explanation to the apparent oil spill size dependency of the BE.

Herein, the goal is to establish a model that describes the vaporization order of crude oil burning on water. Wellestablished models from literature were used to make qualitative predictions for four burning parameters: the surface temperature $\left(T_{s}\right)$, flame height $\left(L_{F}\right)$, burning rate $(\dot{m})$ and the residue composition. Experimental data from fresh crude oil and alkane burning experiments were then compared to the model predictions to determine the best fitting model for the vaporization order of crude oil. Using this model, the obtained burning efficiencies were analyzed for the tested scale and for large scale results from the literature.

\section{Conceptual Model Overview}

In a recent comprehensive review on ISB, the Equilibrium Flash Vaporization (EFV) model was proposed for the vaporization order of burning crude oil [24]. This model was earlier proposed by Petty [21] and describes the vaporization of a multicomponent fuel as being of "essentially constant composition" with a constant vaporization rate. Thus, all components evaporate simultaneously, here defined as a uniform vaporization order, and each individual component contributes to the vaporization rate relative to its concentration in the oil. Characteristics of this model are that the crude oil burns with constant $T_{s}$ at a constant $\dot{m}$, has a temperature gradient in the oil slick and lighter components are present in the residue [21, 24]. 
An alternative to the EFV model was proposed by Buist et al. [22], based on their studies on crude oil residues. Their results showed that crude oil residues had an increased concentration of heavy hydrocarbon fractions $\left(T_{b}>\right.$ $538{ }^{\circ} \mathrm{C}$ ) and complete removal of the light hydrocarbon fractions $\left(T_{b}<204{ }^{\circ} \mathrm{C}\right)$. This trend was also found in previous studies on crude oil residue compositions [22, 25, 26]. Buist et al. [22] suggested that the burning proceeded according to an Imperfect EFV model in which lighter oil fractions are favored over heavier oil fractions during the burning. Thus, for this model the relative vaporization rate of lighter components is higher than their relative concentrations. Apart from this difference, the model follows the EFV model and as such features a constant vaporization rate and uniform vaporization order.

Also, three models have been developed for the vaporization of multicomponent fuels based on the Peclet number for mass diffusion $\left(P e_{m}\right)$ (Eq. (1)) [23]. The value of $P e_{m}$ of a fuel determines which of these three models is the most appropriate to describe the vaporization [27]. Although these models were not developed specifically for the burning of crude oils, they describe the general vaporization process of multicomponent fuels in great detail.

$$
P e_{m}=\frac{K}{D_{l}}=\frac{\text { vaporization rate }}{\text { mass diffusion rate }}
$$

For fuels where $P e_{m}$ approaches infinity, usually due to a negligible mass diffusion such as in solids, the composition of the fuel is fixed and no internal changes occur during the combustion. This means that the fuel is burned layer by layer and hence this model is known as the Onion Skin model. The vaporization order depends on the internal distribution of the compounds, e.g. uniformly or by density, and will be fuel dependent.

For fuels where $P e_{m}$ approaches zero, the fuel can be considered to have a uniform distribution of its components due to its relatively high mass diffusion rate. As a result, the vaporization order depends only on the relative volatility differences of the compounds. This model is known as the Batch Distillation model and describes the fuel as being burned compound by compound with decreasing volatility [28]. Because the volatility 
is in general inversely proportional to the molecular weight for hydrocarbons, the vaporization order of this model is effectively in order of increasing molecular weight.

For fuels with a low, non-zero $P e_{m}$ value the vaporization is controlled by the concentration boundary layers [23, $29,30]$. At the start of the combustion, the most volatile compound at the surface will determine the vaporization rate by its volatility, like the batch distillation model. However, when its surface concentration becomes too low to support this vaporization rate, the vaporization becomes controlled by the mass diffusion rate of this compound. Because the mass diffusion is much slower, the less volatile compounds at the surface will now also be able to contribute significantly to the vaporization rate. Thus, compounds do not evaporate one at a time, but rather a small amount of compounds with similar volatility evaporate simultaneously. The vaporization order is the same as for the Batch Distillation model, i.e. from the most volatile to the least volatile compound. In this study, we will refer to this model as the diffusion-limited vaporization (DLV) model.

Because of the substantial amount of light hydrocarbons present in crude oil, it is unlikely that the onion skin model correctly describes the vaporization order. The onion skin model has only been associated with water-inoil emulsions, as there is no mass diffusion between the water and oil components [23, 31]. For heavily weathered crude oils (emulsified and evaporation of the lighter fractions) solid-like behavior has also been observed during flame spread experiments [13]. The onion skin model may therefore be a suitable model for highly viscous and weathered oils. However, this study focuses on fresh crude oil and as such the onion skin model is not considered relevant herein.

The vaporization orders of the four remaining models are classified in two order types (uniform and volatilitycontrolled) and two sub-orders per vaporization order type, as summarized in Table 1. Each model has a unique combination of burning parameters that distinguishes between the vaporization orders and sub-orders so that these can be used to identify the correct model for a certain fuel. The modeling of these burning parameters is discussed in detail in the following section. 


\begin{tabular}{|c|c|c|c|c|}
\hline \multirow[b]{2}{*}{ Model } & \multicolumn{2}{|c|}{ Vaporization } & \multirow{2}{*}{$\begin{array}{l}\text { Vaporization order } \\
\text { burning parameters }\end{array}$} & \multirow{2}{*}{$\begin{array}{l}\text { Vaporization sub-order } \\
\text { burning parameters }\end{array}$} \\
\hline & Order & Sub-order & & \\
\hline $\begin{array}{l}\text { EFV } \\
\text { Imperfect } \\
\text { EFV }\end{array}$ & $\begin{array}{l}\text { Constant rate } \\
\text { and uniform } \\
\text { order }\end{array}$ & $\begin{array}{l}\text { Vapor composition } \\
\text { equal to fuel } \\
\text { Relatively more light } \\
\text { components }\end{array}$ & $\begin{array}{l}\text { Constant surface } \\
\text { temperature } \\
\text { Constant burning rate } \\
\text { \& flame height }\end{array}$ & $\begin{array}{l}\text { Unchanged residue } \\
\text { composition } \\
\text { Residue depleted of light } \\
\text { components }\end{array}$ \\
\hline $\begin{array}{l}\text { Batch } \\
\text { Distillation }\end{array}$ & $\begin{array}{l}\text { In order of } \\
\text { decreasing } \\
\text { volatility }\end{array}$ & $\begin{array}{l}\text { One component at a } \\
\text { time } \\
\text { Several components } \\
\text { at a time }\end{array}$ & $\begin{array}{l}\text { Increasing surface } \\
\text { temperature } \\
\text { Decreasing burning rate } \\
\text { \& flame height }\end{array}$ & $\begin{array}{l}\text { Abrupt transition from } \\
\text { burned to unburned } \\
\text { components in residue } \\
\text { Concentration gradient } \\
\text { from burned to unburned } \\
\text { components in residue }\end{array}$ \\
\hline
\end{tabular}

\subsection{Modeling of burning parameters}

Model predictions of the burning parameters for crude oil were carried out by combining the vaporization order of the models with the general properties of hydrocarbons and correlations between $\dot{m}$ and $L_{F}$ for liquid pool fires. In general, hydrocarbons show an increasing $T_{b}$ with increasing molecular weight [32]. As a result, the $T_{s}$ of a pool fire is expected to increase when the molecular weight of the hydrocarbon fuel increases. On the other hand, $\dot{m}$ and the heat of combustion $\left(\Delta H_{C}\right)$ generally decrease with molecular mass, based on experimental results (e.g. [33, 34]). These two properties are correlated to $L_{F}$ according to Eq. (2) and the empirical correlation for $L_{F}$ of a pool fire as established by Heskestad (Eq. (3)) $[35,36]$. In Eq. (2), $\dot{Q}_{c}$ is the heat release rate and $\chi_{c}$ is the combustion efficiency, which is usually around 0.6-0.7 for hydrocarbon pool fires [37]. In Eq. (3), $D$ is the pool diameter and is assumed to be a constant for the purposes of this study. From these equations it becomes clear that for hydrocarbons with increasing weight, as $\dot{m}$ and $\Delta H_{c}$ decrease, $\dot{Q}_{c}$ will decrease and thus $L_{F}$ will decrease as well.

$$
\begin{gathered}
\dot{Q}_{c}=\chi_{c} \cdot \dot{m} \cdot \Delta H_{c} \\
L_{F}=0.235 \dot{Q}_{c}^{2 / 5}-1.02 D
\end{gathered}
$$


Because the models provide a clear description of the molecular composition of the evaporating gases from the fuel, the aforementioned correlations can be used to predict the $T_{s}, L_{F}$ and $\dot{m}$ of a fresh crude oil burning on water. Although some of the models lack the numerical details that would allow for quantitative modeling, the qualitative descriptions are sufficient to draft up trends, as visualized in Fig. 1. Combining these trends with the measured residue composition provides sufficient detail to distinguish between the four models for a given fuel, as discussed below and shown in Table 1. The data presented in Fig. 1 do not represent actual values but only show the relative differences among the four models. The data were normalized for the model with the highest expected values for $T_{s}, L_{F}$ and $\dot{m}$ (y-axis) and the burning time from ignition to extinction of the flame (x-axis).
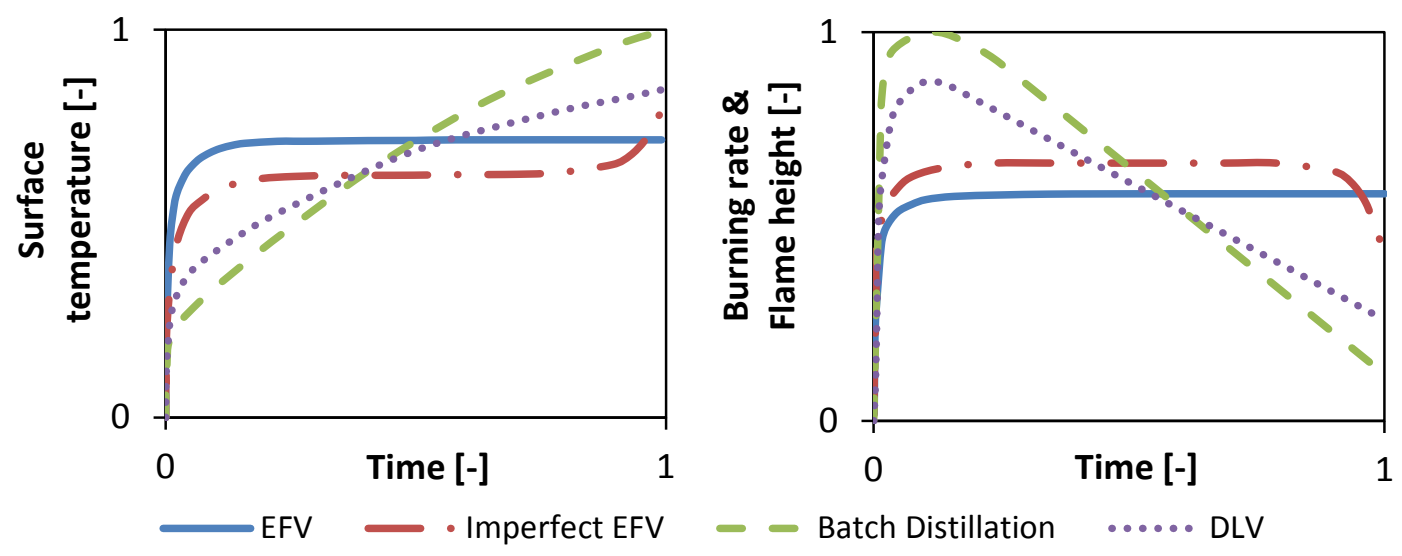

Figure 1. Crude oil combustion model predictions of $T_{s}$ (left) and $\dot{m}$ and $L_{F}$ (right). Due to the similarities between $\dot{m}$ and $L_{F}$ in the trends predicted by the models they are both represented by the same plot.

In the EFV and Imperfect EFV models the vaporization has a constant rate and composition and thus the crude oil essentially burns as if it consists of only a single component. This behavior results in constant values for $T_{s}, L_{F}$ and $\dot{m}$ after the initial growing phase of the fire (Fig. 1). These constant values of the burning parameters represent the average of the respective values of all the evaporating components. For the EFV model, this average lies in the range of the middle hydrocarbon fraction $\left(T_{b}\right.$ of $204-538^{\circ} \mathrm{C}$ [22]), whereas the average for the Imperfect EFV model should lie closer to the light hydrocarbon fraction ( $T_{b} \leq 204{ }^{\circ} \mathrm{C}$ [22]). As a result, $T_{s}$ will be 
lower and $L_{F}$ and $\dot{m}$ will be higher for the Imperfect EFV model compared to the EFV model, as seen in Fig. 1. Once the lighter components have been burned off the fuel in the Imperfect EFV model, the fire will either extinguish or the combustion will shift to the heavier fractions (depicted in Fig. 1).

The vaporization order of decreasing volatility for the Batch Distillation and DLV models implies that the combustible gases evaporating from the fuel have an increasing molecular weight as a function of time. Thus, these models feature an increasing $T_{s}$ and decreasing $L_{F}$ and $\dot{m}$ (Fig. 1). Combustion in the Batch Distillation model starts with the single most volatile component and the evaporating gases shift abruptly from one component to the other. In the DLV model, the combustion gases start with a mixture of volatile compounds and the composition changes gradually as components are removed and introduced to the mixture one at a time. Thus, the initial $T_{s}$ value is lower and the initial $L_{F}$ and $\dot{m}$ values are higher in the Batch Distillation model than in the DLV model (Fig. 1) and the Batch Distillation model features a steeper slope for these parameters. Still, the most important aspect of these models is that they in principal do not reach a steady state burning phase because the gases in the combustion zone constantly change composition. This feature is the main distinction between the volatility order models and the EFV type models.

In order to distinguish between the two EFV type models or between the two volatility order models, the residue composition can be used. The residue composition can be predicted by expressing it as a function of the vaporization order and the burning time. For a uniform vaporization order (EFV model) the chemical composition of the crude oil does not change during the burning. Thus, the residue composition is independent of time and is the same as the starting composition. For a near-uniform vaporization order (Imperfect EFV model) the components with a relative vaporization rate higher than their relative concentration will have a reduced concentration in the residue compared to the fresh crude oil. The burning time determines the concentration of these components in the residue, up to the point when they are completely removed. Thus, an unchanged or reduced concentration of the lighter components in the residue can be used as the characterizing distinction between the EFV model and the Imperfect EFV model. 
For a vaporization order of decreasing volatility (Batch Distillation and DLV model), the burning time determines up to which point in the volatility order the individual components participate in the burning. Because lighter components are generally more volatile, the unburned components mainly consist of heavier hydrocarbons. The components are removed one at a time from the burning oil for the Batch Distillation model and as such the residue composition features an abrupt change between removed and present components. The removal of components from the burning oil goes more gradually for the DLV model, resulting in a concentration gradient for the partially burned components between the fully removed and unburned components in the residue. Depending on the burning time, the abrupt switch and gradient move more towards the heavier components. The difference between an abrupt concentration change and a concentration gradient in the burning residue is the characterizing distinction between the Batch Distillation model and the DLV model.

\section{Experimental Method}

All experiments were performed following the procedures described in van Gelderen et al. [9]. Hence, only a short description of the procedures is given here. In order to measure the surface temperature and flame height, a $160 \mathrm{~mm}$ diameter Pyrex Glass Cylinder (PGC) was placed on an open metal foot in a $1.0 \times 1.0 \times 0.50 \mathrm{~m}^{3}$ water basin to contain the oil (Fig 2). The open foot allowed water to move freely at the bottom of the PGC and thus to maintain the level of the oil surface constant for a longer period of time. To measure the burning rate, the PGC was placed on an open foot in a $0.30 \times 0.30 \times 0.40 \mathrm{~m}^{3}$ metal bucket filled with water, which stood on a scale with a reading interval of $1 \mathrm{~g}$ and two second data acquisition intervals. For all experiments, a known amount of oil, corresponding to an initial thickness of 10-40 mm, was poured carefully on the water in the PGC. A thermocouple array was then placed in position to measure the temperature at the oil surface and at $2,3,5$, $10,20,30,40$, and $50 \mathrm{~mm}$ below the surface. All oils were ignited with a butane hand torch. After the flame extinguished, the residue was collected with hydrophobic absorption pads and weighed so that the burning efficiency could be calculated. 


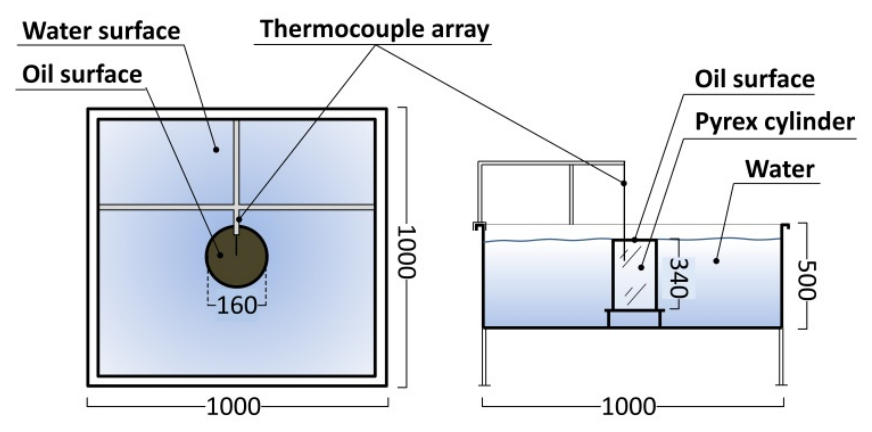

Figure 2. Schematic of the experimental setup used to test $T_{S}$ and $L_{F}$. All units are in millimeters. For additional schematics see van Gelderen et al. [9].

Burning parameters $\left(T_{s}, \dot{m}, L_{F}\right.$ and the residue composition) were measured for three alkanes ( $n$-octane, dodecane and hexadecane), a mixture of these alkanes (1:1:1 volumetric ratio) and two crude oils (DUC and REBCO) (Table 2). The alkanes were studied to provide a benchmark for the model predictions and a reference for the crude oil experiments. Pure fuels have by definition a uniform vaporization order and thus can be used to test the model predictions for the EFV type models. The alkane mixture was studied to test if such a simplified, but more well-defined multicomponent fuel, could be used to represent the complex multicomponent character of the crude oils.

\begin{tabular}{lcc}
\hline \multicolumn{2}{l}{ Table 2. Experimental matrix } & \\
\hline Oil type & $\begin{array}{c}\text { Thickness } \\
(\mathrm{mm})\end{array}$ & $\begin{array}{c}\text { Parameter(s) } \\
\text { tested }\end{array}$ \\
n-Octane/Dodecane & 10 & $T_{s}$ \\
n-Octane/Dodecane & 40 & $\dot{m}, L_{F}$ \\
Hexadecane & 20 & $T_{s}, \dot{m}, L_{F}$ \\
Alkane mixture & 15 & $T_{s}$ \\
Alkane mixture & 30 & $\dot{m}, L_{F}$ \\
DUC/REBCO & 10 & $T_{s}$ \\
DUC/REBCO & 40 & $\dot{m}, L_{F}$ \\
\hline
\end{tabular}


Oil characteristics of the oils are shown in Table 3. Experiments were conducted with different slick thicknesses because a thin initial slick thickness $(\leq 15 \mathrm{~mm}$ ) had less height difference in oil surface level, so it was easier to measure $T_{s}$, whereas the thicker slicks $\left(20-40 \mathrm{~mm}\right.$ ) provided better results for $\dot{m}$ and $L_{F}$ (Table 2). Hexadecane could not be ignited at an initial slick thickness of $10 \mathrm{~mm}$ and hence was only tested for an initial slick thickness of $20 \mathrm{~mm}$. The ignition occurred instantly for the crude oils and $n$-octane, whereas the ignition time was a few seconds for the alkane mixture, 15-60 seconds for dodecane (depending on the water temperature) and over two minutes for hexadecane.

\begin{tabular}{|c|c|c|c|c|}
\hline Oil & Density $(g / m l)^{a}$ & Boiling point $\left({ }^{\circ} \mathrm{C}\right)$ & Flashpoint $\left({ }^{\circ} \mathrm{C}\right)^{b}$ & Viscosity $(c P)^{a}$ \\
\hline$n$-Octane & 0.699 & $125-126$ & 13 & 0.386 \\
\hline Dodecane & 0.745 & $215-217$ & 71 & 1.294 \\
\hline Hexadecane & 0.770 & 287 & 135 & 3.036 \\
\hline DUC & 0.853 & $230+$ & 7 & 6.750 \\
\hline REBCO & 0.863 & $300+$ & 23 & 12.400 \\
\hline \multicolumn{5}{|c|}{ a Measured at $25^{\circ} \mathrm{C}$ using an Anton Paar SVM 3000 viscometer. } \\
\hline \multicolumn{5}{|c|}{${ }^{\mathrm{b}}$ Measured using a Pensky-Martens Flash Point Tester: PM 4 (closed cup). } \\
\hline
\end{tabular}

A camera was used to capture the flame height of the burning oils. Videos of the flames were converted to a series of binary pictures with an interval of 3-6 seconds, resulting in 500-600 data points. To reduce scatter in the data caused by flame puffing, the average of every 10 data points was taken to represent the value of the flame height with 50-60 data points for each experiment. For additional information on the data acquisition and processing of $L_{F}$, see van Gelderen et al. [9].

The chemical composition of DUC, REBCO, their residues and the alkane mix residues were analyzed on an Agilent 6890 Gas Chromatograph (GC) with a Flame Ionization Detector, equipped with a 7683 autosampler and 
a $30 \mathrm{~m}$ ZB5 column ( $0.25 \mathrm{~mm}$ internal diameter and $0.25 \mu \mathrm{m}$ film thickness). The samples were dissolved in dichloromethane $(2.0 \mathrm{~g} / \mathrm{L})$ for injection. The inlet temperature was $310^{\circ} \mathrm{C}$ and $1 \mu \mathrm{L}$ was injected in split mode (5:1) and held for $2 \mathrm{~min}$. Hydrogen was used as carrier gas with a flow rate of $2.0 \mathrm{~mL} / \mathrm{min}$ and the detector setup had a temperature of $300{ }^{\circ} \mathrm{C}$, hydrogen flow rate of $35 \mathrm{~mL} / \mathrm{min}$, air flow of $350 \mathrm{~mL} / \mathrm{min}$ and nitrogen makeup flow of $40 \mathrm{~mL} / \mathrm{min}$. The initial oven temperature $\left(40{ }^{\circ} \mathrm{C}\right)$ was held for $2 \mathrm{~min}$, then increased to $310^{\circ} \mathrm{C}$ at a rate of $15^{\circ} \mathrm{C} / \mathrm{min}$ and held for $10 \mathrm{~min}$ (total analysis time of $30 \mathrm{~min}$ ).

\section{Results and Discussion}

\subsection{Vaporization order}

The experimental results for $T_{s}$ for the alkanes, alkane mixture and crude oils are shown in Fig 3 . The data are up to the point where the surface thermocouple was no longer attached to the surface due to thinning of the slick as the burning progressed. Disconnection of a thermocouple from the fuel surface was clearly visible in the temperature data from a sudden spike in the measured temperature, indicating a transition from measuring liquid to gas temperatures. Overall, the $T_{s}$ measurements showed good repeatability (error bars $<10 \%$ from the average temperature) for both the pure and multicomponent fuels (Fig 3).

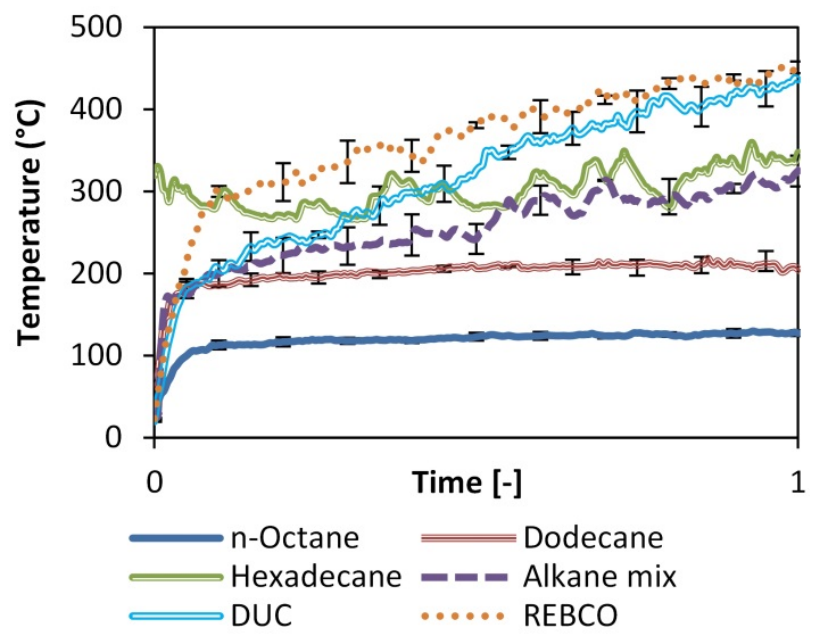

Figure 3. Experimental data of the surface temperature $\left(T_{s}\right)$ for the alkanes, alkane mixture and crude oils. 
For the alkanes the $T_{s}$ data are close to their respective $T_{b}$ values, which provide a measure of validity to the method used to collect the $T_{s}$ data. Hexadecane proved difficult to ignite as it suffered from significant heat losses to the water, which is reflected in the scattered $T_{s}$ data and high starting $T_{s}$. The $T_{s}$ clearly increased over time for the crude oils. This result indicates that these multicomponent fuels followed a volatility controlled vaporization order. In addition, the increasing $T_{s}$ of these fuels are in clear contrast with the constant trends of the alkanes, which provided a representation of an EFV type vaporization order. For the alkane mixture, the $T_{s}$ shows an initial increase up to the point where it reaches the $T_{b}$ of hexadecane. After this point, at about $190 \mathrm{~s}$ ( $\mathrm{t}$ $=0.55$ in Fig. 3), the burning seemed to reach an equilibrium state dominated by hexadecane. Because the total burning duration for the $15 \mathrm{~mm}$ alkane mixture was about 1130 seconds, it is unlikely that the mixture was depleted of $n$-octane and dodecane after $190 \mathrm{~s}$. Thus, the vaporization of the alkane mixture is closer to an EFV type model than to a volatility controlled model.

Experimental results for $\dot{m}$ and $L_{F}$ of the alkanes, alkane mixture and crude oils are shown in Fig 4 . The burning rate data was corrected to only show the oil burning rate by deducing the water loss rate from the total burning rate, assuming a constant rate for the water evaporation. The mass balance between the residue weight and total weight lost showed that between $60-250 \mathrm{~g}$ of water evaporated, depending on the burning time and thus the fuel layer thickness. The hexadecane $(20 \mathrm{~mm})$ burned for 27 minutes, the alkane mixture $(30 \mathrm{~mm})$ and $n$ alkane $(40 \mathrm{~mm})$ for about 35 minutes and the dodecane $(40 \mathrm{~mm})$, DUC $(40 \mathrm{~mm})$ and REBCO (40) burned for about 50 minutes. Data points represent an averaged value over approximately 2\% (30-60 seconds) and 3\% (4590 seconds) of the burning time for $L_{F}$ and $\dot{m}$, respectively. 

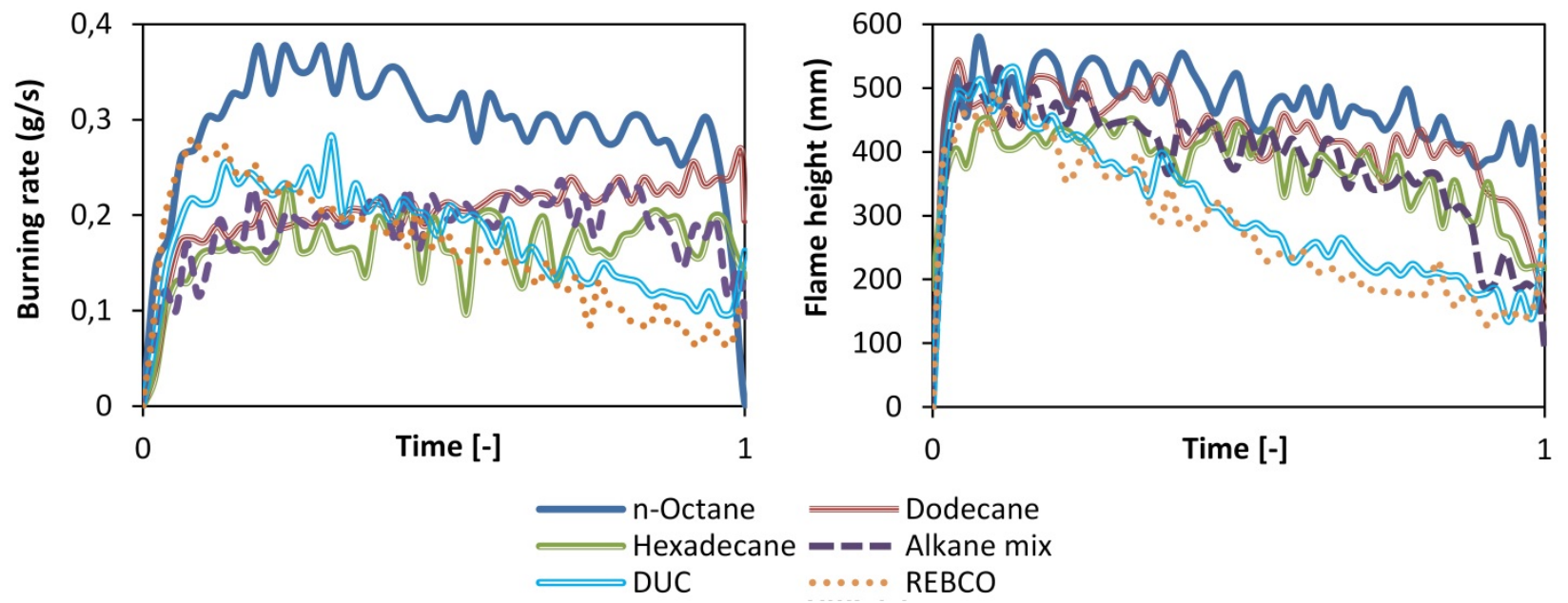

Figure 4. Experimental data of the burning rate $(\dot{m})$ and flame height $\left(L_{F}\right)$ for the alkanes, alkane mixture and crude oils. Data points are presented as lines for clarity reasons.

For each fuel, the same trends are observed between its $\dot{m}$ and $L_{F}$ in Fig. 4 , as expected. Again, the alkane results provide a reasonable representation of an EFV type vaporization. Near-constant values were observed for the alkanes with some minor declines after approximately half of the burning duration. This decrease in $\dot{m}$ and $L_{F}$ is likely caused by increasing heat losses to the water as the oil layer thickness decreases during the burning. For dodecane, however, a minor increase in $\dot{m}$ was observed. Because its $L_{F}$ shows the same declining trend as $n$ octane and hexadecane, this increasing $\dot{m}$ was contributed to an increasing evaporation rate of the surrounding water as the burning progressed. While this implies that a constant water loss rate is incorrect, no better alternative was found to correct the oil burning rate. Because it was found that the water loss did not significantly alter the results [9], this phenomenon was not further investigated. In addition, the alkane data clearly shows that hydrocarbons with a higher molecular weight resulted in lower $\dot{m}$ and $L_{F}$ values, thus verifying some of the theories used for the model predictions in Section 2.1.

The crude oil data differed significantly from the alkane data. The crude oils initially show similar values for $\dot{m}$ and $L_{F}$ as $n$-octane, after which they rapidly decreased to values below those of hexadecane. These decreasing 
trends match well with the volatility order model predictions and combined with the $T_{s}$ data clearly indicate that the crude oils had a vaporization order of decreasing volatility.

The alkane mixture again showed values close to dodecane and hexadecane, indicating that the evaporating gases consisted of a mixture of all the components. As the combustion became dominated by hexadecane after approximately $70 \%$ of the burning time, it seems that the lightest components, $n$-octane, had been mostly depleted at this time. This suggests that the mixture followed a near-uniform vaporization order. Although $L_{F}$ shows a decreasing trend, this could be explained by heat losses to the water layer and depletion of $n$-octane rather than a volatility controlled vaporization order.

GC chromatograms of fresh REBCO crude oil, a typical REBCO residue and a typical alkane mixture residue are shown in Fig. 5. The shown crude oil chromatograms are representative for both fresh crude oils and their burn residues. Estimates of the residue thicknesses and obtained burning efficiencies are shown in Table 4. The crude oil data clearly shows that fresh REBCO consisted of a large amount of light and medium weight hydrocarbons that were almost completely absent in the residue. This type of residue composition matches well with what would be expected of a volatility controlled vaporization order. The components in the range between $\mathrm{C}_{14}-\mathrm{C}_{31}$ in the residue were only partially removed. These components were still present in the residue but their concentration ratios to the $C_{31}$ concentration had decreased compared to the fresh crude oil. The resulting concentration gradient clearly indicates that, of the two volatility controlled vaporization models, the diffusionlimited vaporization model best matches the pool burning of a crude oil. The alkane mixture residue consisted mainly of hexadecane (99.6\%) with only a trace amount of dodecane $(0.4 \%)$ and contained no $n$-octane. Both $n$ octane and dodecane were clearly evaporated preferentially over hexadecane, yet were present up to at least half of the burning duration, as suggested by the other results (Figs. 3 and 4). These results indicate that the alkane mixture had a near-uniform vaporization order and that the Imperfect EFV model best matches the pool burning of an alkane mixture. 

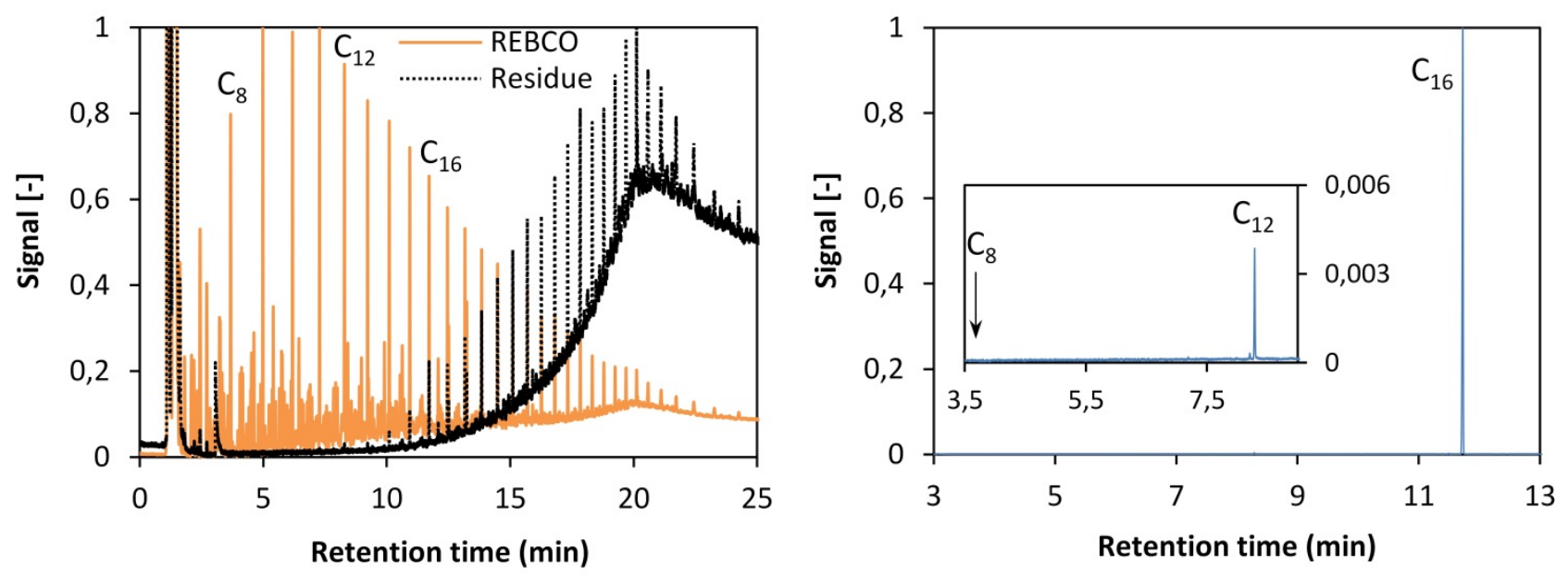

Figure 5. GC chromatograms of Fresh REBCO and a typical REBCO residue (left) and a typical alkane mixture residue (right).

\begin{tabular}{|c|c|c|c|}
\hline \multirow[t]{2}{*}{ Oil type } & \multicolumn{2}{|c|}{ Thickness ( $\mathrm{mm}$ ) } & \multirow{2}{*}{$\begin{array}{c}\text { Burning } \\
\text { Efficiency (\%) }\end{array}$} \\
\hline & Initial & Final $^{1}$ & \\
\hline$n$-Octane & $10 / 40$ & $0.1 / 0.05$ & 99/99 \\
\hline Dodecane & $10 / 40$ & $0.2 / 0.9$ & $94 / 97$ \\
\hline Hexadecane & 20 & 0.4 & 87 \\
\hline Alkane mixture & $15 / 30$ & $2.1 / 1.0$ & $77 / 92$ \\
\hline DUC & $10 / 40$ & $1.5 / 5.7$ & $60 / 79$ \\
\hline REBCO & $10 / 40$ & $1.6 / 7.9$ & $52 / 75$ \\
\hline
\end{tabular}

However, experimental work on multicomponent and crude oil droplet combustion has shown somewhat different results for the vaporization controlling mechanisms. Ikegami et al. [38] showed that the combustion of crude oil droplets followed a distillation-like vaporization mechanism, even though the theoretical Peclet number indicated that the vaporization was diffusion-limited. This discrepancy was contributed to the "violent inter-circulation of fuel" caused by droplet swellings and contractions and gas generation and nucleation inside the droplet. Such processes are not expected to have a significant effect on the circulation within pool fires, so 
that the Peclet number would be determining the vaporization mechanism. Therefore, the vaporization mechanism for crude oil pool fires on water would indeed be diffusion-limited, as indicated by the data.

According to experiments on multicomponent droplets of two and three components, these types of fuels have a mixture of a distillation-like and diffusion-limited vaporization mechanism [30, 39]. In these experiments, the droplets went through several steady state burning phases, each during which a new component was added to the vaporization. Although the lightest component evaporated preferentially at the start of the burning, it was still present at the last stages of the burning. When comparing these results to the performed pool fire experiments that have much longer burning times, it is not surprising that such a vaporization mechanism can be approximated with a near-uniform vaporization order. The narrow range of components in the alkane mixture would quickly lead to a steady state in which all components evaporate simultaneously. Such a steady state would remain until the lightest component(s) are depleted from the fuel near the end of the combustion. Thus, even though the alkane mixture might have a volatility controlled vaporization order, a near-uniform vaporization order is a representative approximation for pool fires, as shown by the experimental results. This approximate near-uniform vaporization order may also apply to other fuels with a narrow range of hydrocarbons such as refined fuels (gasoline or diesel). However, multicomponent fuels with a very wide range of components were shown to have significantly different behavior during the burning. The crude oils had a much more prominent volatility controlled vaporization order and can therefore not be represented by multicomponent fuels with only a narrow range of components.

\subsection{Burning efficiency analysis}

With the best vaporization models established, an attempt was made to explain the size dependency of the burning efficiency for crude oils. In the experimental results, several of the deviations from the expected trends were attributed to heat losses to the water layer. These heat losses have been shown to influence the burning 
behavior of a pool fire $[10,40]$. Here, the heat transfer balance of the tested pool fires was combined with the vaporization models in an attempt to explain the obtained burning efficiencies.

Figure 6, which is adapted from Hamins et al. [41], shows the main heat transfer mechanics for a burning oil pool on water. The energy to the fuel is provided by the heat feedback from the flame and therefore depends on the size of the flame. The total net energy $\left(\dot{Q}_{n e t}\right)$ transferred to the fuel consists of the incoming convective $\left(\dot{Q}_{\text {conv }}\right)$ and radiative $\left(\dot{Q}_{\text {rad }}\right)$ heat from the flame, minus any reflection from the fuel surface $\left(\dot{Q}_{\text {ref }}\right)$ (Eq. (4)) [42]. Because the Pyrex glass area exposed to hot fuel is small compared to the area of the fuel-water interface, any conductive heat transfer from the pool confinement ring is considered negligible. The net incoming energy is divided amongst the energy used to evaporate the fuel $\left(\dot{Q}_{\text {evap }}\right)$, heating of the bulk of the fuel as a consequence of the thermal gradient between the fuel surface and the oil-water interface $\left(\dot{Q}_{\text {grad }}\right)$ and the heat losses to the water $\left(\dot{Q}_{\text {loss }}\right)$. The two main mechanics that reduce the available energy for evaporation over time are $\dot{Q}_{\text {grad }}$ and $\dot{Q}_{\text {loss }}$. Re-radiation from the pool surface is typically small compared to $\dot{Q}_{\text {evap }}$ and was therefore omitted for clarity purposes [41]. Usually, $\dot{Q}_{\text {loss }}$ is also considered to be small but due to the presence of water as a heat sink this term becomes more prominent [40]. Thus, the energy available at any given time for evaporation of the liquid fuel is given by Eq. (5).

$$
\begin{aligned}
& \dot{Q}_{n e t}=\dot{Q}_{c o n v}+\dot{Q}_{r a d}-\dot{Q}_{r e f} \\
& \dot{Q}_{\text {evap }}=\dot{Q}_{n e t}-\dot{Q}_{\text {grad }}-\dot{Q}_{\text {loss }}
\end{aligned}
$$




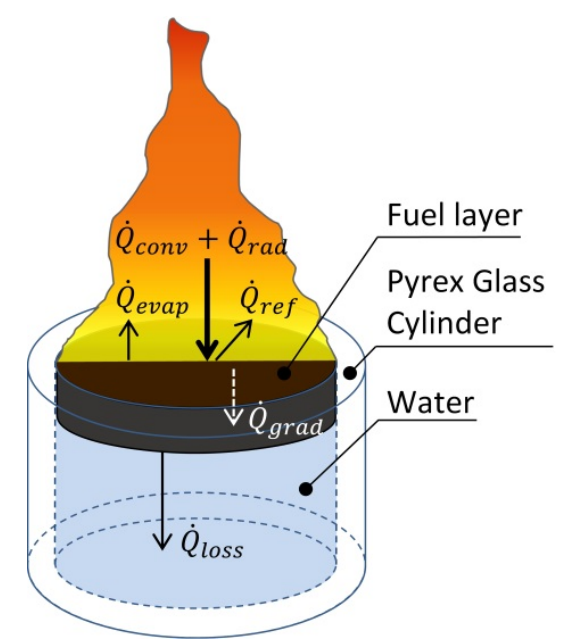

Figure 6. Schematic of the main heat transfer mechanics for a confined oil pool burning on water. Adapted from Hamins et al. [41]. The re-radiative heat transfer from the oil surface was omitted for clarity reasons as the focus is on the heat exchange between the flame, oil and water.

For the alkane fuels, the results show that a semi-steady state is reached shortly after ignition. For such a state, $\dot{Q}_{n e t}$ can be assumed to be constant. Over time the temperature gradient in the fuel layer, and therefore $\dot{Q}_{g r a d}$, also typically remained constant for a long duration of the burning (Fig. 7). Only $\dot{Q}_{\text {loss }}$, which is a function of the temperature difference between the fuel layer and water layer, will increase over time as the slick thickness is reduced and the hot fuel surface starts to approach the water layer. As $\dot{Q}_{\text {loss }}$ increases, $\dot{Q}_{\text {evap }}$ decreases up to the point where it becomes too low to maintain an evaporation rate that can sustain the fire. At this 'critical point' the fire is extinguished and a residue is left on the water. Because larger hydrocarbons generally show lower flame heights and higher surface temperatures (Figs. 3 and 4), it is likely that their $\dot{Q}_{n e t}$ is lower and $\dot{Q}_{\text {grad }}$ and $\dot{Q}_{\text {loss }}$ are higher. The critical point can therefore be expected to be reached relatively faster, which is reflected in the lower burning efficiencies and higher residue thicknesses in Table 4 for dodecane and hexadecane. For thicker slicks, it takes longer for the hot surface to approach the water layer and the increase in $\dot{Q}_{\text {loss }}$ is slower. Thus, relatively more fuel can be burned before the critical point is reached and therefore the burning efficiencies are higher for thicker initial slicks. 


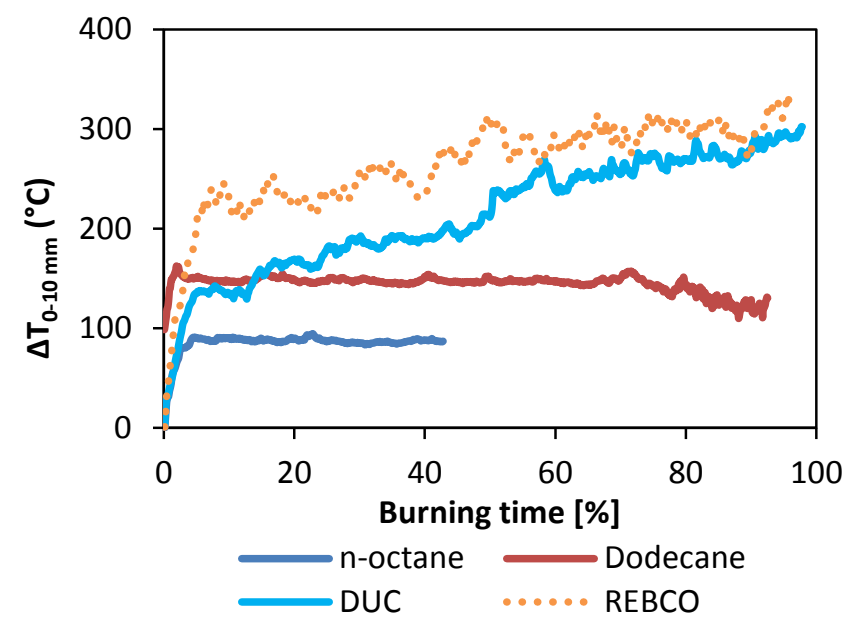

Figure 7. Temperature difference between the fuel surface and the temperature $10 \mathrm{~mm}$ below the fuel surface (initial oil-water interface) for fuels with an initial slick thickness of $10 \mathrm{~mm}$ as a function of the burning time. The data shown is up to the moment when the thermocouple placed at the fuel surface no longer measured the surface temperature. The temperature gradients were representative for the temperature gradients in the fuels between all measured locations below the fuel surface $(2,3,5$ and $10 \mathrm{~mm})$.

Whereas the critical point for the alkane fuels is mostly determined by the balance between $\dot{Q}_{\text {evap }}$ and $\dot{Q}_{\text {loss }}$, the heat transfer mechanics are more complicated for the crude oils. Because the crude oils were shown to have a volatility controlled vaporization order, $\dot{Q}_{n e t}$ and $\dot{Q}_{\text {grad }}$ cannot be assumed to be constant. Over the course of the burning, the flame height for the crude oils was reduced by $70 \%$ (Fig. 4), which would result in a reduction of $\dot{Q}_{n e t}$ over time. As shown in Fig. 7, the temperature gradient inside the crude oils increased over time, causing $\dot{Q}_{\text {grad }}$ to increase, which was also observed in an earlier study [43]. Furthermore, the crude oils reached higher temperatures than the alkane fuels, both at the surface (Fig. 3) and the oil-water interface (Figs. 3 and 7), so $\dot{Q}_{\text {loss }}$ also was more significant. These heat transfer mechanics lead to $\dot{Q}_{\text {evap }}$ being reduced in an increasingly faster rate over time. The critical point can therefore be reached well before the crude oil has been fully burned, which explains the low burning efficiencies. Thus, in order to reach high burning efficiencies for crude oils, the accumulative effect of a decreasing flame height (and thus $\left.\dot{Q}_{n e t}\right)$ and increasing heat losses $\left(\dot{Q}_{\text {grad }}\right.$ and $\left.\dot{Q}_{\text {loss }}\right)$ needs to be overcome. 
The effect of $\dot{Q}_{\text {loss }}$ on $\dot{Q}_{\text {evap }}$ can also be expressed mathematically by incorporating $\dot{Q}_{\text {loss }}$ in the expression for the energy balance of pool fires without an underlying water layer [42]. Hamins et al. [42] showed that for a system with no heat losses, $\dot{Q}_{\text {evap }}$ mainly depends on the intrinsic parameters of a fuel because $\dot{Q}_{n e t}$ becomes independent of $\dot{m}$ (and thus of $L_{F}$ ). Without heat losses, $\dot{Q}_{\text {net }}$ becomes only a function of $\dot{Q}_{\text {evap }}$ and $\dot{Q}_{\text {grad }}$. The energy needed to evaporate a fuel depends on its latent heat of vaporization $\left(\Delta H_{v}\right)$ and the burning rate, while the energy used to heat up the bulk of a fuel depends on its specific heat $\left(c_{p}\right)$, the difference between the surface temperature $\left(T_{S}\right)$ and the ambient temperature $\left(T_{\infty}\right)$, and the burning rate. The effective heat of gasification $\left(\Delta H_{g}\right)$ was defined as a combination of these terms (see also Spalding [44], Spalding [45]), resulting in Eq. (6):

$$
\dot{Q}_{n e t}=\dot{Q}_{\text {evap }}+\dot{Q}_{\text {grad }}=\dot{m} \cdot \Delta H_{v}+\dot{m} \cdot c_{p} \cdot\left(T_{s}-T_{\infty}\right)=\dot{m} \cdot\left(\Delta H_{v}+c_{p} \cdot\left(T_{s}-T_{\infty}\right)\right)=\dot{m} \cdot \Delta H_{g}
$$

The heat feedback to the fuel can also be expressed as a function of $\dot{Q}_{c}$ and a heat feedback fraction $\left(\chi_{s}\right)$, as shown in Eq. (7):

$$
\dot{Q}_{n e t}=\chi_{s} \cdot \dot{Q}_{c}
$$

Using the expression for $\dot{Q}_{c}$ from Eq. (2) for complete combustion of the fuel $\left(\chi_{c}=1\right), \chi_{s}$ was then rewritten to finally yield Eq. (8). Although this equation was developed for pool fires with a steady fuel surface level and not for a regressing fuel layer, the burning rates in the $\dot{Q}_{n e t}$ and $\dot{Q}_{c}$ terms are not expected to differ significantly in the tested system. Equation (8) is therefore expected to be valid for the current problem as well.

$$
\chi_{s}=\frac{\dot{Q}_{n e t}}{\dot{Q}_{c}}=\frac{\dot{m} \cdot \Delta H_{g}}{\dot{m} \cdot \Delta H_{c}}=\frac{\Delta H_{g}}{\Delta H_{c}}
$$


For a pool fire on water, however, the conductive heat losses to the water layer $\left(\dot{Q}_{\text {loss }}\right)$ cannot be assumed to be negligible and should be taken into account in the above equations. Combining Eq. (5) and (6) then results in Eq. (9):

$$
\dot{Q}_{n e t}=\dot{Q}_{\text {evap }}+\dot{Q}_{\text {grad }}+\dot{Q}_{\text {loss }}=\dot{m} \cdot \Delta H_{g}+\dot{Q}_{\text {loss }}
$$

Substituting this expressing for $\dot{Q}_{n e t}$ into Eq. (8) then gives Eq. (10):

$$
\chi_{s}=\frac{\dot{Q}_{n e t}}{\dot{Q}_{c}}=\frac{\dot{m} \cdot \Delta H_{g}+\dot{Q}_{\text {loss }}}{\dot{m} \cdot \Delta H_{c}}=\frac{\Delta H_{g}}{\Delta H_{c}}+\frac{\dot{Q}_{l o s s}}{\dot{m} \cdot \Delta H_{c}}
$$

Since $\dot{Q}_{\text {loss }}$ is not depending on the burning rate, but rather on the mass of the water volume that is heated up, the burning rate cannot be removed from this term. As such, this equation indicates that $\dot{Q}_{\text {loss }}$ increases relative to $\dot{Q}_{\text {evap }}$ as a function of decreasing $\dot{m}$, which is the case for crude oils (Fig. 4).

It has been shown that the burning rate per unit area increases with increasing diameter for $0.1<D>2.0 \mathrm{~m}[42$, 46]. The heat loss term in Eq. (10) is therefore less significant for large scale fires than for small scale fires. This equation thus provides a possible explanation to the size dependency of the burning efficiency for crude oil when the increased burning rate per unit area balances out against the increasing heat losses. The critical point would not be reached until the final stages of the burning when the slick becomes very thin and $\dot{Q}_{l o s s}$ starts to dominate the heat transfer mechanics. The burning efficiency of a fuel burning on water, when limited by $\dot{Q}_{\text {loss }}$, will therefore be a function of the pool diameter.

The current results indicate that fuels with low volatilities are more limited by $\dot{Q}_{\text {loss }}$ than high volatility fuels, because more energy is required to evaporate the fuel and thus $\dot{Q}_{\text {evap }}$ needs to be larger. This suggests that insitu burning of weathered crude oils, which have lower volatilities than fresh crude oils, is also limited by $\dot{Q}_{l o s s}$. Burning efficiencies for weathered oils have indeed been shown to be size dependent (see e.g. Fritt-Rasmussen 
et al. [14] and Brandvik et al. [17]). The principles of this heat transfer model can therefore likely be applied to the in-situ burning of crude oil on water in general, independent of the state (weathered or fresh) of the oil.

\section{Conclusions}

The comparison between model predictions and experimental results for the surface temperature, burning rate, and flame height of crude oil pool fires on water showed that the crude oil had a volatility controlled vaporization order. Crude oil residue compositions showed that this order was furthermore diffusion-limited, meaning that several components evaporate simultaneously from the fuel as the evaporating components shift from most volatile to least volatile. The alkane mixture, studied as an alternative, simplified substitute for crude oil with a more narrow range and limited number of components, showed significantly different results from the crude oil. Whereas the crude oil did not reach a steady state burning, the alkane mixture results were similar to the steady-state behavior of the pure alkane fuels. The alkane mixture was better described by a near-uniform vaporization order, where all components in the fuel evaporate simultaneously but with a relatively higher vaporization rate for the lighter components. This shows that simplified fuels with a narrow range of hydrocarbons do not accurately represent crude oils, because the burning behavior of a multicomponent fuel depends on the (volatility) range of its components. Thus, great caution should be taken when making statements about oil burning based on simplified experiments.

The established vaporization model was used in combination with a model for the heat transfer balance to give an explanation for the size dependency of the burning efficiency for crude oils. Heating of the fuel surface and a decreasing flame height over time, caused by the volatility controlled vaporization order, increase the heat losses while less energy is supplied to the fuel through heat feedback from the flame. These heat transfer mechanics reduce the energy available for the evaporation of the fuel, until the fire is no longer self-sustaining, causing it to extinguish prematurely, as compared with predictions based on adiabatic models. Because the 
burning rate per unit area increases with increasing diameter, large scale experiments have more energy available to overcome the increasing heat losses. As a consequence, more heat remains available for evaporating the crude oil and, as a result, large scale experiments would result in higher burning efficiencies than small scale experiments. This predicted increase in burning efficiency with increasing oil spill size is in line with experimental values from the literature.

While the heat transfer mechanics were not studied quantitatively herein, the results gave an indication of its importance. A detailed study of the heat transfer mechanics, both in small and large scale experiments, would be highly relevant for understanding the burning efficiency of in-situ burning of crude oils on water.

\section{Acknowledgements}

The authors would like to thank the Danish Council for Independent research for funding the project (Grant DDF

- 1335-00282). COWIfonden funded the construction of the Crude Oil Flammability Apparatus and Maersk Oil provided the crude oils that were used in this study. None of the sponsors have been involved in the results and conclusions of this paper. The authors would also like to thank Dr. Janne Fritt-Rasmussen, Dr. Pierrick Mindykowski and Rolff Ripke Leisted for valuable discussions.

\section{References}

[1] AMAP, Assessment 2007: Oil and Gas Activities in the Arctic - Effects and Potential Effects, Vol. 1, AMAP, Oslo, Norway, 2010.

[2] Nuka, Research \& Planning Group, LLC., Oil Spill Prevention and Response in the U.S. Arctic Ocean: Unexamined Risks, Unacceptable Consequences, The PEW Environment Group, Washington, D.C., 2010. 
[3] M. Fitzpatrick, U.S. Coast Guard Arctic Pollution Response Research and Development, in: OCEANS '85 Ocean Engineering and the Environment, IEEE, (1985), pp. 863-865.

[4] A.B. Nordvik, The Technology Windows-of-Opportunity for Marine Oil Spill Response as Related to Oil Weathering and Operations, Spill Sci. Technol. Bull. 2 (1995), pp. 17-46.

[5] I. Buist, J. McCourt, S. Potter, S. Ross, and K. Trudel, In Situ Burning, Pure Appl. Chem. 71 (1999), pp. 43-65.

[6] M.F. Fingas, K. Li, F. Ackerman, M.C. Bissonnette, P. Lambert, R. Nelson, G. Halley, P.R. Campagna, N. Laroche, P. Jokuty, R.D. Turpin, M.J. Trespalacios, J. Belanger, N. Vanderkooy, E.J. Tennyson, D. Aurand, and R. Hiltrabrand, The Newfoundland Offshore Burn Experiment - NOBE, in: In Situ Burning Oil Spill Workshop Proceedings, NIST, (1994), pp. 63-70.

[7] H. Farmahini Farahani, X. Shi, A. Simeoni, and A.S. Rangwala, A Study on Burning of Crude Oil in Ice Cavities, Proc. Combust. Inst. 35 (2015), pp. 2699-2706.

[8] J.L. Torero, S.M. Olenick, J.P. Garo, and J.P. Vantelon, Determination of the Burning Characteristics of a Slick of Oil on Water, Spill Sci. Technol. Bull. 8 (2003), pp. 379-390.

[9] L. van Gelderen, N.L. Brogaard, M.X. Sørensen, J. Fritt-Rasmussen, A.S. Rangwala, and G. Jomaas, Importance of the Slick Thickness for Effective In-Situ Burning of Crude Oil, Fire Saf. J. 78 (2015), pp. 1-9.

[10] T.A. Brzustowski and E.M. Twardus, A Study of the Burning of a Slick of Crude Oil on Water, Symp. (Int.) Combust. 19 (1982), pp. 847-854.

[11] C.C. Guénette, P. Sveum, C.M. Bech, and I.A. Buist, Studies of In Situ Burning of Emulsions in Norway, in: International Oil Spill Conference Proceedings, IOSC, (1995), pp. 115-122.

[12] A.Y. Walavalkar and A.K. Kulkarni, Combustion of water-in-oil emulsion layers supported on water, Combust. Flame 125 (2001), pp. 1001-1011.

[13] N. Wu, G. Kolb, and J.L. Torero, The Effect of Weathering on the Flammability of a Slick of Crude Oil on a Water Bed, Combust. Sci. Technol. 161 (2000), pp. 269-308. 
[14] J. Fritt-Rasmussen, P.J. Brandvik, A. Villumsen, and E.H. Stenby, Comparing Ignitability for In Situ Burning of Oil Spills for an Asphaltenic, a Waxy and a Light Crude Oil as a Function of Weathering Conditions Under Arctic Conditions, Cold Reg. Sci. Technol. 72 (2012), pp. 1-6.

[15] J. Fritt-Rasmussen and P.J. Brandvik, Measuring Ignitability for In Situ Burning of Oil Spills Weathered Under Arctic Conditions: From Laboratory Studies to Large-Scale Field Experiments, Mar. Pollut. Bull. 62 (2011), pp. $1780-1785$.

[16] A.A. Allen, Contained Controlled Burning of Spilled Oil During the Exxon Valdez Oil Spill, Environment Canada (1990), pp. 305-313.

[17] P.J. Brandvik, P.S. Daling, L.-G. Faksness, J. Fritt-Rasmussen, R.L. Daae, and F. Leirvik, Experimental Oil Release in Broken Ice - A Large-Scale Field Verification of Results from Laboratory Studies of Oil Weathering and Ignitability of Weathered Oil Spills, Report No. 26, SINTEF, Trondheim, 2010.

[18] S. Potter, Tests of Fire-Resistant Booms in Low Concentrations of Drift Ice - Field experiments May 2009., Report No. 27, SINTEF, Trondheim, 2010.

[19] M. Fingas, Introduction to Oil Chemistry and Properties, in, Mervin Fingas (Ed.), Oil Spill Science and Technology, Gulf Professional Publishing, Oxford, 2011, pp. 51-59.

[20] AMAP, Assessment 2007: Oil and Gas Activities in the Arctic - Effects and Potential Effects, Vol. 2, AMAP, Oslo, Norway, 2010.

[21] S.E. Petty, Combustion of Crude Oil on Water, Fire Saf. J. 5 (1983), pp. 123-134.

[22] I. Buist, K. Trudel, J. Morrison, and D. Aurand, Laboratory Studies of the Properties of In-Situ Burn Residues, in: International Oil Spill Conference Proceedings, IOSC, (1997), pp. 149-156.

[23] C.K. Law, Combustion Physics, Cambridge University Press, New York, 2006, 722.

[24] I.A. Buist, S.G. Potter, B.K. Trudel, S.R. Shelnutt, A.H. Walker, D.K. Scholz, P.J. Brandvik, J. Fritt-Rasmussen, A.A. Allen, and P. Smith, In Situ Burning in Ice-Affected Waters: State of Knowledge Report, Final Report 7.1.1, Arctic Response Technology, 2013. 
[25] R.M. Garrett, C.C. Guénette, C.E. Haith, and R.C. Prince, Pyrogenic Polycyclic Aromatic Hydrocarbons in Oil Burn Residues, Environ. Sci. Technol. 34 (2000), pp. 1934-1937.

[26] J. Fritt-Rasmussen, B.E. Ascanius, P.J. Brandvik, A. Villumsen, and E.H. Stenby, Composition of In Situ Burn Residue as a Function of Weathering Conditions, Mar. Pollut. Bull. 67 (2013), pp. 75-81.

[27] A. Makino and C.K. Law, On the Controlling Parameter in the Gasification Behavior of Multicomponent Droplets, Combust. Flame 73 (1988), pp. 331-336.

[28] C.K. Law, Multicomponent Droplet Combustion With Rapid Internal Mixing, Combust. Flame 26 (1976), pp. 219-233.

[29] C.K. Law, Internal Boiling and Superheating in Vaporizing Multicomponent Droplets, AIChE J. 24 (1978), pp. 626-632.

[30] C.H. Wang, X.Q. Liu, and C.K. Law, Combustion and Microexplosion of Freely Falling Multicomponent Droplets, Combust. Flame 56 (1984), pp. 175-197.

[31] C.K. Law, A Model for the Combustion of Oil/Water Emulsion Droplets, Combust. Sci. Technol. 17 (1977), pp. 29-38.

[32] G. Egloff, J. Sherman, and R.B. Dull, Boiling Point Relationships among Aliphatic Hydrocarbons, J. Phys. Chem. 44 (1940), pp. 730-745.

[33] P.L. Blackshear and K.A. Murty, Some Effects of Size, Orientation, and Fuel Molecular Weight on the Burning of Fuel-Soaked Wicks, Symp. (Int.) Combust. 11 (1967), pp. 545-552.

[34] E.S. Domalski, Selected Values of Heats of Combustion and Heats of Formation of Organic Compounds Containing the Elements C, H, N, O, P, and S, J. Phys. Chem. Ref. Data 1 (1972), pp. 221-277.

[35] G. Heskestad, Luminous heights of turbulent diffusion flames, Fire Saf. J. 5 (1983), pp. 103-108.

[36] D. Drysdale, Diffusion Flames and Fire Plumes, in, An Introduction to Fire Dynamics, John Wiley \& Sons, Ltd, New York, 2011, pp. 121-179. 
[37] A. Tewarson, Experimental Evaluation of Flammability Parameters of Polymeric Materials, in, Menachem Lewin, S. M. Atlas, and Eli M. Pearce (Eds.), Flame - Retardant Polymeric Materials: Volume 3, Springer New York, Boston, MA, 1982, pp. 97-153.

[38] M. Ikegami, G. Xu, K. Ikeda, S. Honma, H. Nagaishi, D.L. Dietrich, and Y. Takeshita, Distinctive Combustion Stages of Single Heavy Oil Droplet Under Microgravity, Fuel 82 (2003), pp. 293-304.

[39] A.L. Randolph, A. Makino, and C.K. Law, Liquid-Phase Diffusional Resistance in Multicomponent Droplet Gasification, Symp. (Int.) Combust. 21 (1988), pp. 601-608.

[40] M. Arai, K. Saito, and R.A. Altenkirch, A Study of Boilover in Liquid Pool Fires Supported on Water Part I: Effects of a Water Sublayer on Pool Fires, Combust. Sci. Technol. 71 (1990), pp. 25-40.

[41] A. Hamins, S.J. Fischer, T. Kashiwagi, M.E. Klassen, and J.P. Gore, Heat Feedback to the Fuel Surface in Pool Fires, Combust. Sci. Technol. 97 (1994), pp. 37-62.

[42] A. Hamins, T. Kashiwagi, and R.R. Burch, Characteristics of pool fire burning, in: Fire Resistance of Industrial Fluids, ASTM International, (1995), pp. 15-41.

[43] A. Vali, D.S. Nobes, and L.W. Kostiuk, Fluid motion and energy transfer within burning liquid fuel pools of various thicknesses, Combust. Flame 162 (2015), pp. 1477-1488.

[44] D.B. Spalding, Some Fundamentals of Combustion, Butterworths, London, 1955, 250.

[45] D.B. Spalding, The Burning Rate of Liquid Fuels from Open Trays by Natural Convection, Fire Res. Abstr. Rev. 4 (1962), pp. 234-236.

[46] H.C. Hottel, Review - Certain Laws Governing Diffusive Burning of Liquids, by V. I. Blinov and G. N. Khudiakov, Fire Res. Abstr. Rev. 1 (1958), pp. 41-44. 